\begin{tabular}{|c|c|}
\hline Title & $\begin{array}{l}\text { Unique heparan sulfate from shrimp heads exhibits a strong inhibitory effect on infections by dengue virus and Japanese } \\
\text { encephalitis virus }\end{array}$ \\
\hline Author(s) & $\begin{array}{l}\text { Chen, Jiancheng; Y amada, Shuhei; Hama, Y oshiki; Shetty, A jaya Kumar; Kobayashi, Takanari; Oda, Hiroshi; Seiki, } \\
\text { Kosuke; Kim, Eunmi; Kimura, Takashi; Takahashi, Naonori; Hidari, Kazuya I. P. J.; Suzuki, Takashi; Suzuki, Y asuo; } \\
\text { Sugahara, Kazuyuki }\end{array}$ \\
\hline Citation & $\begin{array}{l}\text { Biochemical and Biophysical Research Communications, 412(1), 136-142 } \\
\text { https://doi.org/10.1016/j.bbrc.2011.07.059 }\end{array}$ \\
\hline Issue Date & 2011-08-19 \\
\hline Doc URL & http:/hdl .handle.net/2115/47200 \\
\hline Type & article (author version) \\
\hline File Information & BBRC412-1_136-142.pdf \\
\hline
\end{tabular}

Instructions for use 


\section{Unique heparan sulfate from shrimp heads exhibits a strong inhibitory effect on infections by dengue virus and Japanese encephalitis virus}

Jiancheng Chen ${ }^{1}$, Shuhei Yamada ${ }^{1, *}$, Yoshiki Hama ${ }^{1}$, Ajaya Kumar Shetty ${ }^{1}$, Takanari Kobayashi ${ }^{1}$, Hiroshi Oda ${ }^{2}$, Kosuke Seiki ${ }^{2}$, Eunmi Kim ${ }^{3}$, Takashi Kimura ${ }^{3}$, Naonori Takahashi ${ }^{4}$, Kazuya I. P. J. Hidari $^{4}$, Takashi Suzuki ${ }^{4}$, Yasuo Suzuki ${ }^{5}$, and Kazuyuki Sugahara ${ }^{1, *}$

${ }^{1}$ Laboratory of Proteoglycan Signaling and Therapeutics, Hokkaido University Graduate School of Life Science, Sapporo 001-0021, Japan

${ }^{2}$ Central Research Institute, Maruha Nichiro Holdings, Inc., Ibaraki 300-4295, Japan

${ }^{3}$ Department of Molecular Pathobiology, Hokkaido University Research Center for Zoonosis Control, Sapporo 001-0020, Japan

${ }^{4}$ Department of Biochemistry, University of Shizuoka, School of Pharmaceutical Sciences and Global COE Program for Innovation in Human Health Sciences, Shizuoka 422-8526, Japan

${ }^{5}$ Department of Biochemical Sciences, College of Life and Health Sciences, Chubu University, Aichi 487-8501, Japan

*Corresponding authors

Shuhei Yamada and Kazuyuki Sugahara

Address: Laboratory of Proteoglycan Signaling and Therapeutics, Graduate School of Life Science, 
Hokkaido University, Frontier Research Center for Post-Genomic Science and Technology, West-11, North-21, Kita-ku, Sapporo, Hokkaido 001-0021, Japan. Tel.: +81-11-706-9055; Fax: +81-11-706-9055; E-mail address: tjohej@sci.hokudai.ac.jp and k-sugar@sci.hokudai.ac.jp

\section{Abbreviations}

2AB, 2-aminobenzamide; AT-III, antithrombin III; DEN-2, dengue virus type 2; FGF, fibroblast growth factor; GAG, glycosaminoglycan; GlcA, D-glucuronic acid; GlcN, D-glucosamine; GlcNAc, $N$-acetyl-D-glucosamine; Hep, heparin; HexA, hexuronic acid; $\Delta$ HexA, 4,5-unsaturated hexuronic acid or 4-deoxy- $\alpha$-L-threo-hex-4-enepyranosyluronic acid; HGF, hepatocyte growth factor; HPLC, high performance liquid chromatography; HS, heparan sulfate; IdoA, L-iduronic acid; JEV, Japanese encephalitis virus; MK, midkine; PTN, pleiotrophin. 


\section{Abstract}

The structure and biological activities of a highly sulfated heparan sulfate (HS) extracted from shrimp (Penaeus brasiliensis) heads were characterized. Structurally the shrimp HS was more heterogenous than heparin, although it is still highly sulfated. The molecular mass of the shrimp HS preparation was determined to be $32.3 \mathrm{kDa}$ by gel filtration HPLC. Analysis by surface plasmon resonance demonstrated that various growth/differentiation factors specifically bound to the shrimp HS with comparable affinity. Notably, the shrimp HS had a greater inhibitory effect against infections by dengue virus type 2 as well as Japanese encephalitis virus than heparin. Experiments on anticoagulant activity indicated that the shrimp HS exhibited significant anti-thrombin activity, but less than the commercial heparin. Hence, the HS preparation from shrimp heads, an industrial waste, is a prospective agent for a variety of clinical applications.

Keyword: glycosaminoglycans, heparan sulfate, Dengue virus, Japanese encephalitis virus, anticoagulant activity 


\section{Introduction}

Heparan sulfate (HS) and heparin (Hep) are synthesized as proteoglycans, which consist of glycosaminoglycan (GAG) side chains covalently bound to a protein core. They consist of disaccharide repeats of hexuronic acid (HexA) and D-glucosamine (GlcN) $\left([(1 \rightarrow 4)-H e x A-(1 \rightarrow 4) \alpha-G l c N]_{n}\right)$, in which the GlcN residues may be either $N$-sulfated or $N$-acetylated (GlcNAc), and the HexA residues are present as either $\beta$-D-glucuronic acid (GlcA) or the $\mathrm{C}-5$ epimer, $\alpha$-L-iduronic acid. Ester $O$-sulfates principally reside at the $\mathrm{C}-2$ position of iduronic acid and/or C-6 position of GlcN residues, and also occasionally reside at the C-3 position of GlcN residue, giving a significant charge density and structural complexity to the polysaccharide chains [1]. Substantial quantitative differences between HS and Hep exist in iduronic acid content as well as $N$ and $O$-sulfate contents [2].

HS/Hep has a variety of biological functions, such as anti-inflammatory activity, anticoagulant activity, anti-cancer activity, and anti-viral activity [2-4]. Most of these biological activities depend upon interaction between HS/Hep and functional proteins including a wide variety of enveloped and nonenveloped viruses $[5,6]$.

Although Hep is a highly efficacious anticoagulant agent useful for a variety of clinical indications, its multiple bioactivities can have unwanted side effects. Furthermore, in 2008, some pharmaceutical Hep preparations were found to be contaminated with artificial oversulfated chondroitin sulfate and associated with anaphylactoid-type reactions [7-10]. This led to a shortage of 
pharmaceutical Hep and much public concern. Since pharmaceutical Hep is extracted mainly from porcine intestine and bovine lung, any contamination of these resources would be a major problem. Therefore, it is important to develop new substitutes for Hep. Interestingly, a Hep-like HS was reported to exist in shrimp heads, an industrial waste [11]. Therefore, in this study, the structure and biological activities of a HS preparation extracted from shrimp heads were analyzed. 


\section{Materials and methods}

Materials HS from bovine kidney and heparitinase II from Flavobacterium heparinum were purchased from Seikagaku Corp., Tokyo, Japan. Hep from porcine intestine was from Nacalai Tesque, Kyoto Japan. Heparinases I and III from Flavobacterium heparinum were purchased from IBEX, Montreal, Canada. Human thrombin and chromozym TH (Tosyl-glycyl-prolyl-arginine-4-nitranilide acetate) were obtained from Roche, Mannheim, Germany. Human AT-III was from Oxford Biomedical Research (Oxford, MI). Recombinant human (rh)-fibroblast growth factor (FGF)-2 and rh-hepatocyte growth factor (HGF) were purchased from PeproTech EC Ltd. (London, UK) and R\&D Systems (Minneapolis, MN), respectively. rh-FGF-1, rh-pleiotrophin (PTN), and rh-midkine (MK) were from Wako Corp. (Osaka, Japan). Shrimp HS was prepared from $1 \mathrm{~kg}$ of shrimp (Penaeus brasiliensis) heads using the method reported by Dietrich et al. [11].

Disaccharide composition analysis A mixture of heparinases I and III and heparitinase II was incubated with shrimp HS in a total volume of $20 \mu \mathrm{l}$ of $20 \mathrm{mM}$ sodium acetate buffer, $\mathrm{pH} 7.0$, containing $2 \mathrm{mM} \mathrm{Ca}(\mathrm{OAc})_{2}$ at $37^{\circ} \mathrm{C}$ for $1 \mathrm{~h}$. The incubation mixture was heated at $100{ }^{\circ} \mathrm{C}$ for $1 \mathrm{~min}$ to terminate the reaction. Digests were derivatized with 2-aminobenzamide (2AB), and analyzed by anion-exchange HPLC [12]. To examine whether the heparinase/heparitinase-resistant tetrasaccharide sequence containing 3-O-sulfated $\mathrm{GlcN}$ is present in the purified shrimp HS fraction, the 2AB-derivatives of the digest and the tetrasaccharide standards, $\Delta$ HexA $\alpha 1-4 \mathrm{GlcNAc}(6-O-$ sulfate $) \alpha 1-4 \mathrm{GlcA} \beta 1-4 \mathrm{GlcN}(2-N-, 3-O-$ disulfate $)$, 
$\Delta \operatorname{HexA} \alpha 1-4 \mathrm{GlcNAc}(6-O-$-sulfate $) \alpha 1-4 \mathrm{GlcA} \beta 1-4 \mathrm{GlcN}(2-\mathrm{N}-, 3-\mathrm{O}-, 6-\mathrm{O}$-trisulfate),

$\Delta \mathrm{HexA} \alpha 1-4 \mathrm{GlcN}(2-N-, 6-O-d i s u l f a t e) \alpha 1-4 \mathrm{GlcA} \beta 1-4 \mathrm{GlcN}(2-N-, 3-O-, 6-O-$ trisulfate $) \quad$ [13], were subjected to anion-exchange HPLC using a linear $\mathrm{NaH}_{2} \mathrm{PO}_{4}$ gradient from 213 to $803 \mathrm{mM}$ over a 70-min period.

Gel filtration chromatography The molecular mass of the shrimp HS was determined by gel filtration HPLC on a Superdex ${ }^{\mathrm{TM}} 200$ 10/300 GL column (GE Healthcare, Uppsala, Sweden) after treatment with 1.0 $\mathrm{M} \mathrm{NaBH}_{4} / 0.05 \mathrm{M} \mathrm{NaOH}$ to liberate HS chains from the core protein [14].

Measurement of anticoagulant activity Anticoagulant activity was quantified according to the method described previously $[11,15]$. The shrimp HS preparation with $10 \mu$ of human AT-III $(0.1 \mathrm{mg} / \mathrm{ml})$ and $15 \mu \mathrm{l}$ of human thrombin $(0.45 \mathrm{mg} / \mathrm{ml}, 0.63 \mathrm{NIH}$ units $/ \mathrm{ml})$ was incubated in a total volume of $100 \mu \mathrm{l}$ of $45 \mathrm{mM}$ Tris- $\mathrm{HCl}$ buffer containing $225 \mathrm{mM} \mathrm{NaCl}(\mathrm{pH} 8.3)$ at $25^{\circ} \mathrm{C}$ for $30 \mathrm{sec}$. Then, $50 \mu 1$ of chromozym TH (Tosyl-glycyl-prolyl-arginine-4-nitranilide acetate, $1.9 \mu \mathrm{mol} / \mathrm{ml}$ ) was added, and the amidolytic activity of thrombin was determined by measuring the absorbance at 405 $\mathrm{nm}$. The change of absorbance in $200 \mathrm{sec}$ was calculated to evaluate anticoagulant activity. As a positive control, the anticoagulant activity of the commercial Hep preparation (187 units/mg) was investigated.

Analysis of interactions using surface plasmon resonance The interaction of various growth/differentiation factors with the shrimp HS was examined as reported [16], using a BIAcore X system (BIAcore AB, Uppsala, Sweden) at the Open Facility, Hokkaido University Sousei Hall. 
Anti-viral activity of the shrimp HS preparation To investigate the anti-viral activity of the shrimp HS preparation, dengue virus type 2 (DEN-2) and Japanese encephalitis virus (JEV) were used. The anti-DEN-2 and anti-JEV activity was examined according to the method described previously [17]. Briefly, DEN-2 (1,800 focus-forming units/ml as a final concentration) or JEV (Nakayama strain) was premixed with known concentrations of the shrimp HS preparation or Hep (as a positive control). The pre-mixture of virus-GAG was inoculated onto baby hamster kidney-21 (BHK-21) cells grown on a 48 -well plate for $2 \mathrm{~h}$ at $37^{\circ} \mathrm{C}$. After three washes with serum-free Dulbecco's modified Eagle's medium (DMEM), DMEM containing 1\% fetal bovine serum and 0.5\% methyl cellulose was overlayed and the plate was incubated at $37{ }^{\circ} \mathrm{C}$ for 24 or $43 \mathrm{~h}$. Infected foci of cells were visualized by the focus-forming assay and counted under a light microscope [17]. 


\section{Results}

Structural analysis of the shrimp HS preparation The purified shrimp HS was subjected to cellulose acetate membrane electrophoresis [18] and stained with $0.2 \%(\mathrm{w} / \mathrm{v})$ Alcian blue [19]. The component in the shrimp HS preparation was electrophoresed faster than bovine kidney HS and almost to the same position as Hep (data not shown), suggesting that the GAG in the extract of shrimp heads is as negatively charged as Hep.

The disaccharide composition of the shrimp HS preparation was analyzed by enzymatic digestion with a mixture of heparinases I and III and heparitinase II as shown in Fig. 1, and is summarized in Table 1. Structurally the shrimp HS is more heterogenous than bovine kidney HS and Hep. The major disaccharide units of shrimp HS were highly sulfated disaccharide units, $\Delta \operatorname{HexA}(2-O-$ sulfate $) \alpha 1-4 \mathrm{GlcN}(2-N-, 6-O-d i s u l f a t e), \Delta \operatorname{HexA}(2-O$-sulfate $) \alpha 1-4 \mathrm{GlcN}(2-N$-sulfate $)$, and $\Delta$ HexA $\alpha 1-4 \mathrm{GlcN}(2-N-, 6-O-$ disulfate $)$, which accounted for $29 \%, 25 \%$, and $21 \%$, respectively. Since the total proportion of the di- and trisulfated disaccharide units $(75 \%)$ is comparable to that of the trisulfated disaccharide unit in Hep (70\%), the shrimp HS was indeed highly sulfated. This unique and heterogeneous disaccharide composition of HS containing a high proportion of disulfated disaccharides has never been reported.

Since some saccharide sequences containing a 3-O-sulfated GlcN structure are resistant to heparinases and heparitinases [13], the presence of the heparinase/heparitinase-resistant structure in the purified shrimp HS preparation was examined (Fig. 1B). Besides the peaks of HS disaccharides, 
peaks of oligosaccharides were also detected, suggesting the tetrasaccharide sequence containing 3-O-sulfated GlcN to be present in the shrimp HS preparation and to account for $9.6 \%$ (as mole percent) of the digestion products.

The molecular mass of the shrimp HS chain was determined by gel filtration HPLC (Fig. 1C). The major component in the SH preparation was mainly eluted at the elution volume of $14.4 \mathrm{ml}$, and its molecular mass was estimated to be $32.3 \mathrm{kDa}$ using the calibration curve generated with size-defined polysaccharides.

\section{Kinetic analysis of the interaction of various growth/differentiation factors with the}

shrimp HS preparation Since HS-proteoglycans act as a co-receptor for various growth/differentiation factors [22, 23], a kinetic analysis of the interaction of FGF-1, FGF-2, PTN, MK, and HGF with the immobilized shrimp HS was performed using the BIAcore system. The growth/differentiation factors were individually injected at different concentrations onto the surface of the shrimp HS-immobilized sensor chip. Overlaid sensorgrams are shown in Fig. 2. They were analyzed with the software BIAevaluation 4.1 using the "1:1 (Langmuir) binding model" to calculate the kinetic parameters (Table 2). FGF-1, FGF-2, PTN, and MK bound to the shrimp HS preparation, whereas HGF showed no significant binding.

Anticoagulant activity of the shrimp HS preparation The anticoagulant activity of the shrimp HS was investigated (Fig. 3). The shrimp HS preparation also has significant anticoagulant activity but it is much weaker than that of Hep. The activity was completely abolished upon 
digestion with a mixture of heparinases (data not shown), indicating that the anticoagulation was attributable to the HS polysaccharides and not to contaminants in the preparation.

Inhibitory effects on viral infections by the shrimp HS preparation Cell surface HS has been reported to be involved in various viral infections and anti-viral activity of Hep has been demonstrated $[5,6,24,25]$. The inhibitory effect of the shrimp HS preparation on infections by DEN-2 and JEV was examined. As shown in Fig. 4A, shrimp HS inhibited the infection by DEN-2 in a dose-dependent manner. The anti-viral effect was much stronger than that of Hep even at a low concentration $(0.625 \mu \mathrm{g} / \mathrm{ml})$. Similar results were obtained in the experiment with JEV, although the inhibitory activity was comparable to that of Hep (Fig. 4B). The anti-JEV activity was lost completely upon digestion with a mixture of heparinases. These results suggest that the shrimp HS preparation has strong anti-viral (DEN-2 and JEV) activity. 


\section{Discussion}

In this study, a highly sulfated HS was isolated from heads of the shrimp Penaeus brasiliensis, and its structure and biological activity were investigated. The molecular mass of the shrimp HS preparation was approximately 4 times larger than that of shrimp Hep reported by Dietrich et al. [11]. The former appears to be a precursor of the latter, which might be generated by degradation during purification or storage possibly because the shrimp Hep was prepared on a large scale (20 Kg of shrimp heads as the starting material).

The disaccharide composition of the shrimp HS preparation was very different from those of typical HS and Hep derived from bovine kidney and porcine intestine, respectively (Table 1). Shrimp HS has a more heterogenous structure, although it is still highly sulfated. The diverse oligosaccharide sequences organized in the shrimp HS chains appear to contain extensive modifications. It has been considered that HS chains exhibit a domain structure with highly modified and sulfated regions (S-domain) interspersed with low sulfated sequences (NA-domain) [26, 27], and that most Hep/HS-binding proteins specifically interact with saccharide sequences in S-domains [23, 28].

The shrimp HS showed high affinity for FGF-2, MK, and PTN, with $K_{d}$ values of 0.14 , 0.48 , and $0.32 \mathrm{nM}$, respectively (Table 2). Previously $K_{d}$ values for FGF-2, MK, and PTN to bind porcine intestinal Hep were determined as $8.6,204$, and $16.1 \mathrm{nM}$, respectively, with the interaction analysis system IAsys [29]. Kinetic measurements of Hep-binding to PTN made by BIAcore had afforded a $K_{d}$ value of $4 \mathrm{nM}[30]$. Although these results were obtained by different procedures, the 
$K_{d}$ values for Hep are higher than those for shrimp HS, indicating that FGF-2, MK, and PTN bind more strongly to shrimp HS than Hep. Specific saccharide sequences in shrimp HS for the binding to FGF-2, MK-, and PTN appear to have higher affinity to the corresponding growth/differentiation factors than those in Hep, and may be different from them. However, when the values obtained for FGF-1 were compared, the reverse was true. Hep showed a stronger binding to FGF-1 than shrimp HS, suggesting the involvement of distinct sugar sequences between Hep and shrimp HS.

The shrimp HS preparation exhibited significant anticoagulant activity, though it was approximately 4 times weaker than that of Hep. The AT-III-mediated inactivation of thrombin has been demonstrated to depend on the binding of AT-III to a specific pentasaccharide sequence containing a 3-O-sulfated GlcN structure on Hep/HS [31, 32]. Although the digest of the shrimp HS preparation obtained with a mixture of heparinases and heparitinase II contained a higher proportion of heparinase/heparitinase-resistant oligosaccharides presumably containing the $3-O$-sulfated GlcN residue (9.6\% as mole percent) than the digest of Hep (4.4\%) (data not shown), less of the specific pentasaccharide sequence required for the AT-III-binding may be present in the shrimp HS preparation, resulting in reduced anticoagulant activity. However, since HS isolated from industrial waste has weak but significant anticoagulant activity, the shrimp HS preparation should be applicable as an anticoagulant.

Since highly sulfated Hep has been shown to compete with the viral adhesion to target cells [24, 25, 33-35], Hep and related compounds may be useful as anti-viral drugs. Although less sulfated 
than Hep, the shrimp HS showed stronger anti-DEN-2 as well as anti-JEV activity (Fig. 4), suggesting that the binding of HS/Hep does not depend on simple ionic interaction but may occur through a specific saccharide sequence. A specific modification on HS has been demonstrated to contribute to the susceptibility of cells to herpes simplex virus-1 [36, 37]. Shrimp HS seems to contain a unique saccharide sequence responsible for binding to the viral proteins of DEN-2 and JEV comparable with Hep. Characterization of the saccharide sequence in shrimp HS responsible for its anti-DEN-2 and anti-JEV activities, may lead to the development of specific anti-viral drugs.

\section{Acknowledgements}

This work was supported in part by Grants-in-aid for Scientific Research (C) (21590057) (to S. Y.), Scientific Research (B) (23390016) (to K. S.), and the Matching Program for Innovations in Future Drug Discovery and Medical Care (to K. S.) from the Ministry of Education, Culture, Sports, Science, and Technology of Japan (MEXT), and by a Grant for Joint Research (to S. Y.) from the Research Center for Zoonosis Control, Hokkaido University, Japan. 


\section{References}

[1] M. Salmivirta, K. Lidholt, U. Lindahl, Heparan sulfate: a piece of information, FASEB J. 10 (1996) 1270-1279.

[2] L. Kjellén, U. Lindahl, Proteoglycans: structures and interactions, Annu. Rev. Biochem. 60 (1991) 443-475.

[3] M. Bernfield, M. Götte, P.W. Park, O. Reizes, M.L. Fitzgerald, J. Lincecum, M. Zako, Functions of cell surface heparan sulfate proteoglycans, Annu. Rev. Biochem. 68 (1999) 729-777.

[4] S. Yamada, K. Sugahara, Structure of oligosaccharides isolated from heparan sulfate/heparin and substrate specificities of the degrading enzymes of bacterial origin, Trends Glycosci. Glycotechnol. 10 (1998) 95-123.

[5] D. Spillmann, Heparan sulfate: anchor for viral intruders? Biochimie 83 (2001) 811-817.

[6] R.R. Vivès, H. Lortat-Jacob, P. Fender, Heparan sulphate proteoglycans and viral vectors : ally or foe? Curr. Gene Ther. 6 (2006) 35-44.

[7] T.K. Kishimoto, K. Viswanathan, T. Ganguly, S. Elankumaran, S. Smith, K. Pelzer, J.C. Lansing, N. Sriranganathan, G. Zhao, Z. Galcheva-Gargova, A. Al-Hakim, G.S. Bailey, B. Fraser, S. Roy, T. Rogers-Cotrone, L. Buhse, M. Whary, J. Fox, M. Nasr, G.J. Dal Pan, Z. Shriver, R.S. Langer, G. Venkataraman, K.F. Austen, J. Woodcock, R. Sasisekharan, Contaminated heparin associated with adverse clinical events and activation of the contact system, N. Engl. J. Med. 358 (2008) $2457-2467$. 
[8] M. Guerrini, Z. Shriver, A. Bisio, A. Naggi, B. Casu, R. Sasisekharan, G. Torri, The tainted heparin story: an update, Thromb. Haemost. 102 (2009) 907-911.

[9] H. Liu, Z. Zhang, R.J. Linhardt, Lessons learned from the contamination of heparin, Nat. Prod. Rep. 26 (2009) 313-321.

[10] D.B. Blossom, A.J. Kallen, P.R. Patel, A. Elward, L. Robinson, G. Gao, R. Langer, K.M. Perkins, J.L. Jaeger, K.M. Kurkjian, M. Jones, S.F. Schillie, N. Shehab, D. Ketterer, G. Venkataraman, T.K. Kishimoto, Z. Shriver, A.W. McMahon, K.F. Austen, S. Kozlowski, A. Srinivasan, G. Turabelidze, C.V. Gould, M.J. Arduino, R. Sasisekharan, Outbreak of adverse reactions associated with contaminated heparin, N. Engl. J. Med. 359 (2008) 2674-84.

[11] C.P. Dietrich, J.F. Paiva, R.A. Castro, S.F. Chavante, W. Jeske, J. Fareed, P.A. Gorin, A. Mendes, H.B. Nader, Structural features and anticoagulant activities of a novel natural low molecular weight heparin from the shrimp Penaeus brasiliensis, Biochim. Biophys. Acta 1428 (1999) 273-83.

[12] A. Kinoshita, K. Sugahara, Microanalysis of glycosaminoglycan-derived oligosaccharides labeld with fluorophore 2-aminobenzamide by high-performance liquid chromatography: Application to disaccharide composition analysis and exo-sequencing of oligosaccharides, Anal. Biochem. 269, 367-378 (1999)

[13] S. Yamada, K. Yoshida, M. Sugiura, K. Sugahara, K.H. Khoo, H.R. Morris, A. Dell, Structural studies on the bacterial lyase-resistant tetrasaccharides derived from the antithrombin 
III-binding site of porcine intestinal heparin, J. Biol. Chem. 268 (1993) 4780-4787.

[14] K. Sugahara, Y. Ohi, T. Harada, P. de Waard, J.F.G. Vliegenthart, Structural studies on sulfated oligosaccharides derived from the carbohydrate-protein linkage region of chondroitin 6-sulfate proteoglycans of shark cartilage. I. Six compounds containing 0 or 1 sulfate and/or phosphate residue, J. Biol. Chem. 267 (1992) 6027-6035.

[15] T. Maruyama, T. Toida, T. Imanari, G. Yu, R.J. Linhardt, Conformational changes and anticoagulant activity of chondroitin sulfate following its $O$-sulfonation, Carbohydr. Res. 306 (1998) 35-43.

[16] T. Hashiguchi, S. Mizumoto, S. Yamada, K. Sugahara, Analysis of the structure and neuritogenic activity of chondroitin sulfate/dermatan sulfate hybrid chains from porcine fetal membranes, Glycoconjugate J. 27 (2010) 49-60.

[17] C. Aoki, K.I. Hidari, S. Itonori, A. Yamada, N. Takahashi, T. Kasama, F. Hasebe, M.A. Islam, K. Hatano, K. Matsuoka, T. Taki, C.T. Guo, T. Takahashi, Y. Sakano, T. Suzuki, D. Miyamoto, M. Sugita, D. Terunuma, K. Morita, Y. Suzuki, Identification and characterization of carbohydrate molecules in mammalian cells recognized by dengue virus type 2, J. Biochem. 139 (2006) 607-614.

[18] L. Hronowski, T.P. Anastassiades, Quantitation and interaction of glycosaminoglycans with Alcian blue in dimethyl sulfoxide solutions, Anal. Biochem. 93 (1979) 60-72.

[19] L. Hronowski, T.P. Anastassiades, Characterization of glycosaminoglycan-Alcian blue 
complexes by elution from cellulose acetate utilizing different $\mathrm{MgCl}_{2}$ concentrations, Anal. Biochem. 107 (1979) 393-405.

[20] S. Chandrasekhar, M.A. Esterman, H.A. Hoffman, Microdetermination of proteoglycans and glycosaminoglycans in the presence of guanidine hydrochloride, Anal. Biochem. 161 (1987) $103-108$

[21] F. Li, A.K. Shetty, K. Sugahara, Neuritogenic activity of chondroitin/dermatan sulfate hybrid chains of embryonic pig brain and their mimicry from shark liver. Involvement of the pleiotrophin and hepatocyte growth factor signaling pathways, J. Biol. Chem. 282 (2007) 2956-2966.

[22] M. Bernfield, M. Götte, P.W. Park, O. Reizes, M.L. Fitzgerald, J. Lincecum, M. Zako, Functions of cell surface heparan sulfate proteoglycans, Annu. Rev. Biochem. 68 (1999) 729-777.

[23] J. Turnbull, A. Powell, S. Guimond, Heparan sulfate: decoding a dynamic multifunctional cell regulator, Trends Cell Biol. 11 (2001) 75-82.

[24] C.M. Su, C.L. Liao, Y.L. Lee, Y.L. Lin, Highly sulfated forms of heparin sulfate are involved in japanese encephalitis virus infection, Virology 286 (2001) 206-215.

[25] H. Barth, C. Schafer, M.I. Adah, F. Zhang, R.J. Linhardt, H. Toyoda, A. Kinoshita-Toyoda, T. Toida, T.H. Van Kuppevelt, E. Depla, F. Von Weizsacker, H.E. Blum, T.F. Baumert, Cellular binding of hepatitis $\mathrm{C}$ virus envelope glycoprotein E2 requires cell surface heparan sulfate, J. Biol. Chem. 278 (2003) 41003-41012. 
[26] M. Lyon, J.T. Gallagher, Bio-specific sequences and domains in heparan sulphate and the regulation of cell growth and adhesion, Matrix Biol. 17 (1998) 485-493.

[27] A.K. Powell, E.A. Yates, D.G. Fernig, J.E. Turnbull, Interactions of heparin/heparan sulfate with proteins: appraisal of structural factors and experimental approaches, Glycobiology 14 (2004) 17R-30R.

[28] J.R. Bishop, M. Schuksz, J.D. Esko, Heparan sulphate proteoglycans fine-tune mammalian physiology, Nature 446 (2007) 1030-1037.

[29] S.S. Deepa, Y. Umehara, S. Higashiyama, N. Itoh, K. Sugahara, Specific molecular interactions of oversulfated chondroitin sulfate $\mathrm{E}$ with various heparin-binding growth factors. Implications as a physiological binding partner in the brain and other tissues, J. Biol. Chem. 277 (2002) 43707-43716.

[30] M. Fath, V. VanderNoot, I. Kilpeläinen, T. Kinnunen, H. Rauvala, R.J. Linhardt, Interaction of soluble and surface-bound heparin binding growth-associated molecule with heparin, FEBS Lett. 454 (1999) 105-108.

[31] U. Lindahl, L. Thunberg, G. Bäckström, J. Riesenfeld, K. Nordling, I. Björk, Extension and structural variability of the antithrombin-binding sequence in heparin, J. Biol. Chem. 259 (1984) $12368-12376$.

[32] D.H. Atha, A.W. Stephens, R.D. Rosenberg, Evaluation of critical groups required for the binding of heparin to antithrombin, Proc. Natl. Acad. Sci. U. S. A. 81 (1984) 1030-1034. 
[33] D. WuDunn, P.G. Spear, Initial interaction of herpes simplex virus with cells is binding to heparan sulfate, J. Virol. 63 (1989) 52-58.

[34] C.C. Rider, The potential for heparin and its derivatives in the therapy and prevention of HIV-1 infection, Glycoconjugate J. 14 (1997) 639-642.

[35] Y. Chen, T. Maguire, R.E. Hileman, J.R. Fromm, J.D. Esko, R.J. Linhardt, R.M. Marks, Dengue virus infectivity depends on envelope protein binding to target cell heparan sulfate, Nat. Med. 3 (1997) 866-871.

[36] V. Tiwari, C. Clement, D. Xu, T. Valyi-Nagy, B.Y. Yue, J. Liu, D. Shukla, Role for 3-O-sulfated heparan sulfate as the receptor for herpes simplex virus type 1 entry into primary human corneal fibroblasts, J. Virol. 80 (2006) 8970-8980.

[37] R. Copeland, A. Balasubramaniam, V. Tiwari, F. Zhang, A. Bridges, R.J. Linhardt, D. Shukla, J. Liu, Using a 3-O-sulfated heparin octasaccharide to inhibit the entry of herpes simplex virus type 1, Biochemistry 47 (2008) 5774-5783. 


\section{Figure legends}

Fig. 1. Structural characterization of the shrimp HS preparation. The digest of shrimp HS with a mixture of heparinases and heparitinase II were derivatized with 2AB and analyzed by HPLC on an amine-bound silica column using a linear $\mathrm{NaH}_{2} \mathrm{PO}_{4}$ gradient from $16 \mathrm{mM}$ to $538 \mathrm{mM}$ over a 60 -min period (indicated by the dashed line) (A). To detect and quantify the heparinase/heparitinase-resistant oligosaccharides, the $2 \mathrm{AB}$-derivative was analyzed using a linear $\mathrm{NaH}_{2} \mathrm{PO}_{4}$ gradient from $213 \mathrm{mM}$ to $803 \mathrm{mM}$ over a 70-min period (B). The HPLC profile of the highly sulfated oligosaccharide-eluted region is only shown, because the low sulfated disaccharides eluted at around $10-15$ min were not well separated under the HPLC conditions used. The elution positions of the authentic 2AB-labeled unsaturated di- and tetrasaccharides are indicated by numbered arrows: 1, $\Delta$ HexA $\alpha 1-4 \mathrm{GlcNAc} ; 2$, $\Delta$ HexA $\alpha 1-4 G l c N A c(6-O-$ sulfate $) ; \quad 3, \quad \Delta H \operatorname{HexA} \alpha 1-4 \mathrm{GlcN}(2-N$-sulfate); $\quad 4$, $\Delta \mathrm{HexA} \alpha 1-4 \mathrm{GlcN}(2-N-, 6-O-d i s u l f a t e) ; \quad 5, \quad \Delta \operatorname{HexA}(2-O$-sulfate $) \alpha 1-4 \mathrm{GlcN}(2-N$-sulfate $) ; \quad 6$ $\Delta \mathrm{HexA}(2-O$-sulfate $) \alpha 1-4 \mathrm{GlcN}(2-N-, 6-O$-disulfate $) ;$ $\Delta$ HexA $\alpha 1-4 G l c N A c(6-O-$ sulfate $) \alpha 1-4 G l c A \beta 1-4 G l c N(2-N$-,3-O-disulfate); $\Delta$ HexA $\alpha 1-4 G l c N A c(6-O-s u l f a t e) \alpha 1-4 G l c A \beta 1-4 G l c N(2-N-, 3-O-, 6-O-t r i s u l f a t e) ; \quad 9$, $\Delta$ HexA $\alpha 1-4 \mathrm{GlcN}(2-N-, 6-O-d i s u l f a t e) \alpha 1-4 \mathrm{GlcA} \beta 1-4 \mathrm{GlcN}(2-N-, 3-O-, 6-O$-trisulfate). The shrimp HS after treatment with alkali was loaded onto a Superdex ${ }^{\mathrm{TM}} 200$ 10/300 GL column and eluted with 0.2 $\mathrm{M} \mathrm{CH}_{3} \mathrm{COONH}_{4}$ at a flow rate of $0.4 \mathrm{ml} / \mathrm{min}(\mathrm{C})$. Fractions were collected at 1.5 -min intervals, and monitored by the 1, 9-dimethylmethylene blue method $[22,23]$. The column was calibrated using 
size-defined polysaccharides (dextrans, average $M r: 60,000,37,500$, and 18,100) as indicated in the inset. $V_{o}$ and $V_{t}$ represent the void and total volume, respectively.

Fig. 2. Binding of various growth factors to the immobilized shrimp HS. Various concentrations of FGF-2 (A), FGF-1 (B), PTN (C), or MK (D) were injected onto the surface of a shrimp HS-immobilized sensor chip. Sensograms were overlaid using the BIA evaluation software (version 4. 1). Concentrations of each growth factor are shown on the right. Long and short arrows indicate the beginning of the association and dissociation phases, respectively. No significant binding of HGF at $11 \mathrm{nM}$ was detected (E).

Fig. 3. In vitro anticoagulant activity of the shrimp HS and Hep preparations. The shrimp HS (circles) or Hep (squares) preparation was incubated with human AT-III and thrombin at $25^{\circ} \mathrm{C}$ for 30 sec. Then, chromozym TH was added, and the amidolytic activity of thrombin was determined by comparing the absorbance at $405 \mathrm{~nm}$ during $200 \mathrm{sec}$ as described in Materials and methods. Values $($ mean $\pm \mathrm{SD})$ are expressed as percent inhibition of the amidolytic activity of thrombin.

Fig. 4. In vitro anti-viral activity of the shrimp HS. A, DEN-2 was premixed with the shrimp HS or Hep preparation, and then incubated with BHK-21 cells. Infected foci of the cells were visualized by the focus-forming assay and counted. B, JEV (Nakayama strain) was premixed with the shrimp HS, 
Hep, chondroitin sulfate A (CS-A), or the digest of shrimp HS obtained with heparinases, and then incubated with Vero cells. The number of plaques was counted a half day to 1 day later. Values indicate the average \pm SD of the relative infectivity in the presence of GAGs when the infectivity in the absence of GAGs is taken as $100 \%$. Data were obtained from three independent experiments. 
Table 1. Composition of unsaturated disaccharides produced from shrimp HS

\begin{tabular}{|c|c|c|c|}
\hline \multirow[t]{2}{*}{ Unsaturated disaccharides } & Shrimp HS ${ }^{a}$ & Hep & $\begin{array}{c}\text { Bovine } \\
\text { kidney HS }\end{array}$ \\
\hline & \multicolumn{3}{|c|}{$\mathrm{mol} \%$} \\
\hline$\Delta$ HexA $\alpha 1-4 G l c N A c$ & $11 \pm 0.8$ & 3 & 53 \\
\hline$\Delta$ HexA $\alpha 1-4$ GlcNAc(6-O-sulfate) & $9 \pm 0.6$ & 4 & 10 \\
\hline$\Delta$ HexA $\alpha 1-4 \mathrm{GlcN}(2-N$-sulfate $)$ & $5 \pm 0.6$ & 2 & 23 \\
\hline$\Delta$ HexA $\alpha 1-4 \mathrm{GlcN}(2-N-, 6-O$-disulfate $)$ & $21 \pm 1.8$ & 15 & 7 \\
\hline$\Delta \operatorname{Hex} \mathrm{A}(2-O$-sulfate $) \alpha 1-4 \mathrm{GlcN}(2-N$-sulfate $)$ & $25 \pm 3.8$ & 6 & 6 \\
\hline$\Delta \operatorname{HexA}(2-O$-sulfate $) \alpha 1-4 \mathrm{GlcN}(2-N-, 6-O$-disulfate $)$ & $29 \pm 2.9$ & 70 & 1 \\
\hline Sulfate/disaccharide ${ }^{b}$ & 1.93 & 2.58 & 0.62 \\
\hline
\end{tabular}

${ }^{a}$ The values are expressed as the mean \pm S. D. for three independent experiments.

${ }^{b}$ Total sulfate groups/disaccharides are given.

Table 2. Kinetic parameters for the interaction of FGF-2, MK, PTN, and FGF-1 with immobilized shrimp HS

\begin{tabular}{cccc}
\hline Growth factors & $k_{a}$ & $k_{d}$ & $K_{d}$ \\
\hline & $\mathrm{M}^{-1} \mathrm{~S}^{-1}$ & $\mathrm{~S}^{-1}$ & $\mathrm{nM}$ \\
FGF-2 & $(0.91 \pm 0.36) \times 10^{4}$ & $(1.4 \pm 0.95) \times 10^{-6}$ & $0.14 \pm 0.061$ \\
MK & $(6.7 \pm 0.64) \times 10^{3}$ & $(3.1 \pm 0.31) \times 10^{-6}$ & $0.48 \pm 0.072$ \\
PTN & $(1.1 \pm 0.10) \times 10^{4}$ & $(3.5 \pm 1.0) \times 10^{-6}$ & $0.32 \pm 0.083$ \\
FGF-1 & $(1.1 \pm 0.20) \times 10^{4}$ & $(4.0 \pm 0.32) \times 10^{-3}$ & $435 \pm 96$ \\
\hline
\end{tabular}

The kinetic parameters, the association rate constant $\left(k_{a}\right)$, the dissociation rate constant $\left(k_{d}\right)$, and the equilibrium dissociation constant $\left(K_{d}\right)$, were determined using the 'fit kinetics simultaneous $k_{d} / k_{d}$ ' program. The values are expressed as the mean \pm standard error. 


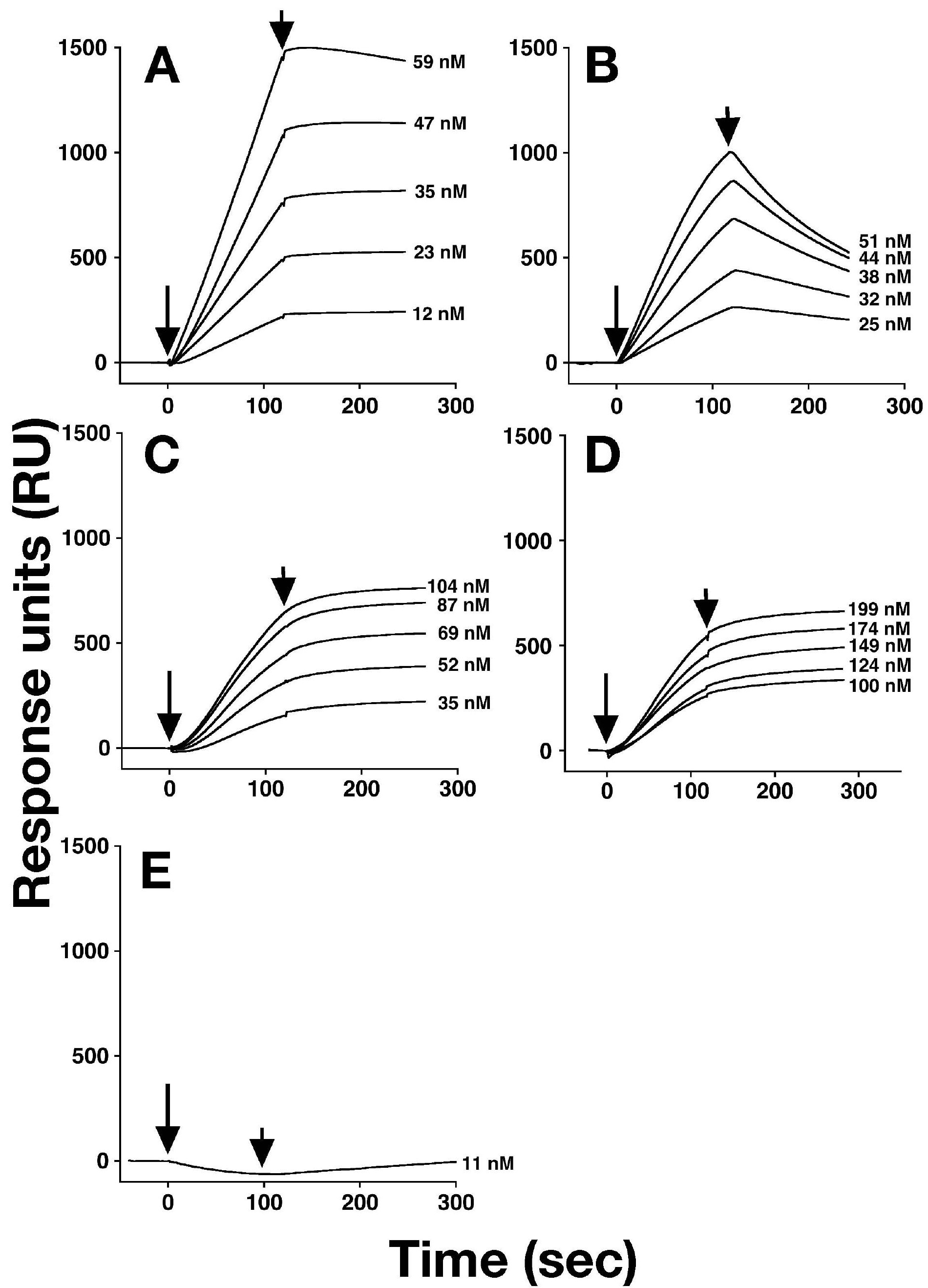




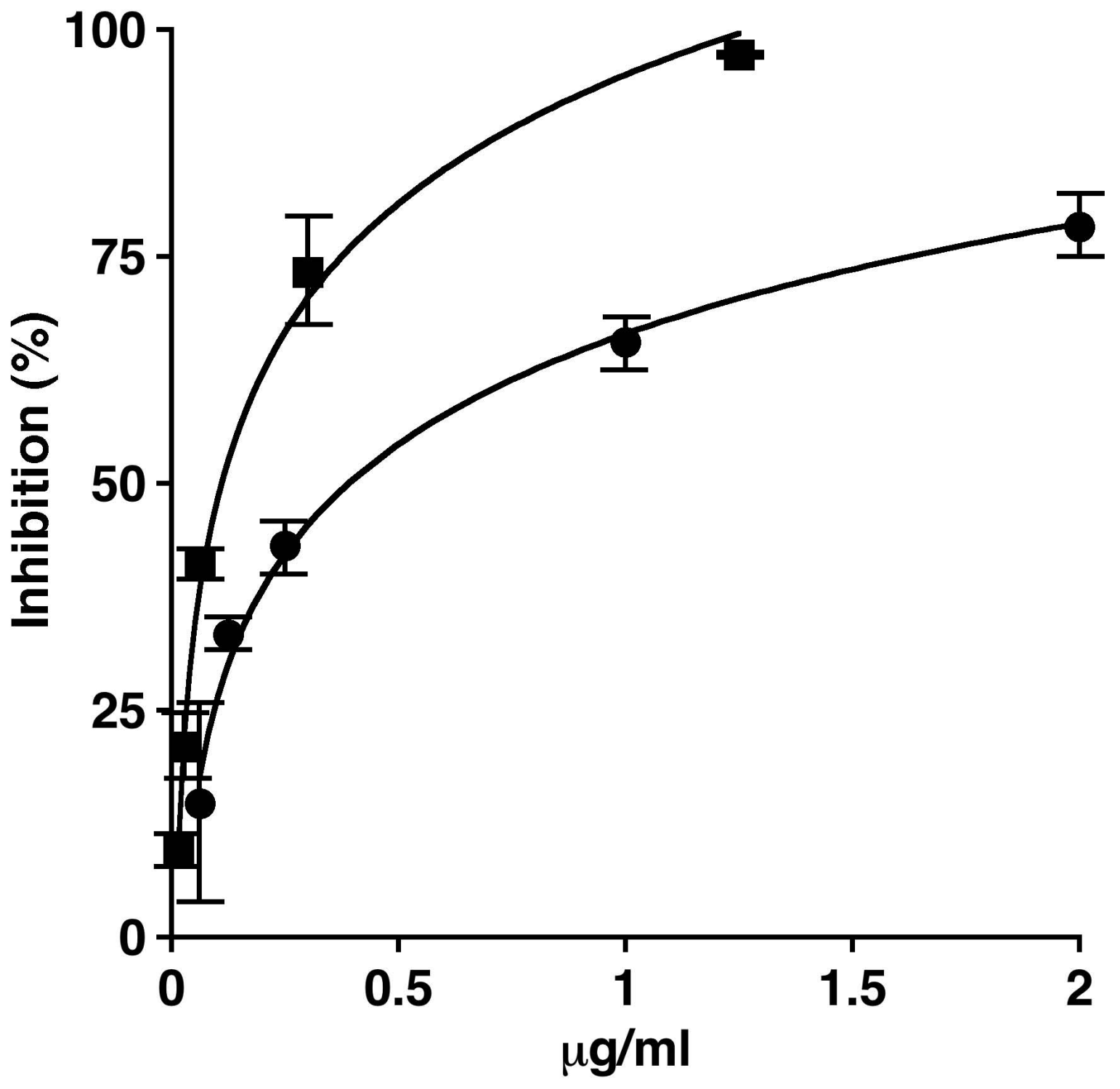




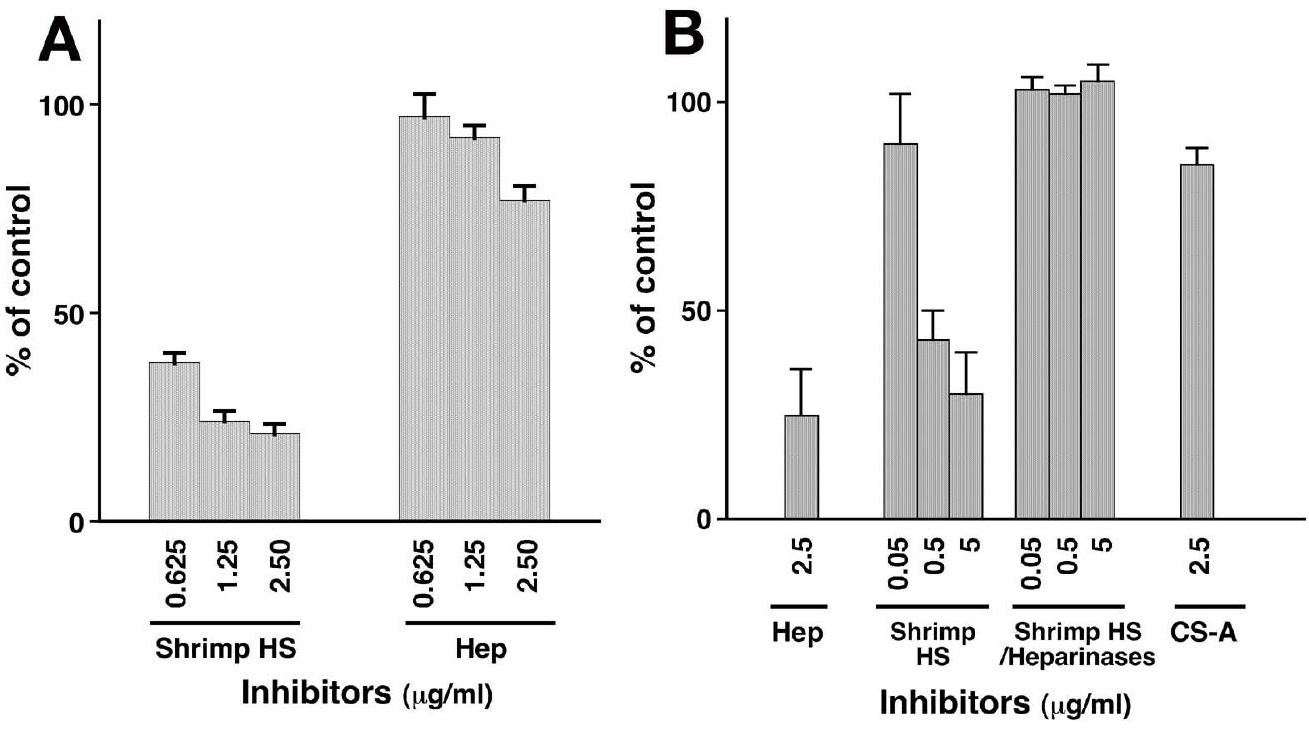

